\title{
Periodic Mechanical Stress Stimulates GIT1-Dependent Mitogenic Signals in Rat Chondrocytes Through ERK1/2 Activity
}

\author{
Kewei Ren ${ }^{\mathrm{a}} \quad$ Jilei Tang ${ }^{\mathrm{b}} \quad$ Xuefeng Jiang $^{\mathrm{a}} \quad$ Huiqing Sun ${ }^{\mathrm{a}} \quad$ Luming Nong $^{\mathrm{c}}$ \\ Nan Shen ${ }^{d}$ Yanqing Gue \\ aDepartment of Orthopedics, the Affiliated Jiangyin Hospital of Southeast University Medical \\ School, Jiangyin, 'Department of Orthopedics, Qidong People's Hospital, Nantong, 'Department \\ of Orthopedics, The Affiliated Changzhou No. 2 People's Hospital with Nanjing Medical University, \\ Changzhou, 'Department of Clinical Pharmacy, the Affiliated Jiangyin Hospital of Southeast University \\ Medical School, Jiangyin, eDepartment of Orthopedics, Nanjing First Hospital, Nanjing Medical \\ University, Nanjing, China
}

\section{Key Words}

Periodic mechanical stress $\bullet$ Chondrocyte proliferation $\bullet$ GIT1 $\bullet$ FAK $・$ Src $・$ Integrin $\beta 1$

\begin{abstract}
Background/Aims: The mitogenic effects of periodic mechanical stress on chondrocytes have been studied extensively, but the mechanisms whereby chondrocytes sense and respond to mechanical stimuli remain to be determined. We explored the question and verified the key role of $\mathrm{G}$ protein coupled receptor kinase interacting protein 1 (GIT1) signaling in periodic mechanical stress-induced chondrocyte proliferation. Methods: Two steps were undertaken in the experiment. In the first step, the cells were maintained under non-pressure conditions or periodic mechanical stress for $1 \mathrm{~h}$ prior to Western blot analysis. In the second step, the cells were pretreated with short hairpin RNA (shRNA) targeted to GIT1 or Src or control scrambled shRNA, or transfected with GIT1 wild-type or GIT1 mutant $\mathrm{Y} 321 \mathrm{~F}$, or focal adhesion kinase (FAK) wild-type or FAK mutants Y397F or Y576F/Y577, respectively. Moreover, the cells were pretreated with blocking antibody against integrin $\beta 1$ or PP2. Then the cells were maintained under non-pressure conditions or periodic mechanical stress for $1 \mathrm{~h}$ prior to Western blot analysis, and for 3 days, $8 \mathrm{~h}$ per day, prior to direct cell counting and CCK-8 assay, respectively. Results: Periodic mechanical stress significantly induced sustained phosphorylation of GIT1 at Tyr ${ }^{321}$. Reduction of GIT1 with shRNA targeted to GIT1 and GIT1 mutant Y321F inhibited periodic mechanical stress-promoted chondrocyte proliferation, accompanied by attenuated extracellular signal-regulated kinase (ERK) $1 / 2$ and FAK phosphorylation at Ty ${ }^{576 / 577}$. However, activation of SrC and FAK-Tyr ${ }^{397}$ was not prevented upon GIT1 suppression. Furthermore, pretreatment with blocking antibody against integrin $\beta 1$, Src-selective inhibitor, PP2, and shRNA targeted to Src blocked GIT1 activation under periodic mechanical stress. In addition,
\end{abstract}

Luming Nong, Nan Shen and Yanqing Gu
Department of Orthopedics, The Affiliated Changzhou No. 2 People's Hospital with Nanjing Medical University, Changzhou 213003 (China)

E-Mail lumingnong@hotmail.com; keweiren@hotmail.com; gyqnjmu@163.com 


\section{Cellular Physiology Cell Physiol Biochem 2018;50:1015-1028

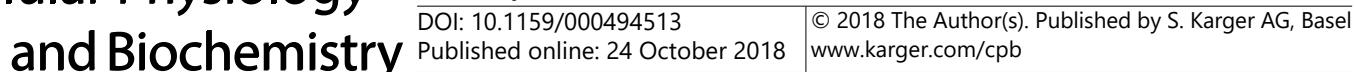 \\ Ren et al.: GIT1-Dependent Mitogenic Signals Through ERK1/2 Activity}

GIT1 phosphorylation at Tyr ${ }^{321}$ was not reduced upon pretreatment with FAK mutants Y397F or Y576F/Y577 under conditions of periodic mechanical stress. Conclusion: These findings collectively suggested that periodic mechanical stress promoted chondrocyte proliferation through at least two separate pathways, integrin $\beta 1-S r c-G I T 1-F A K\left(T y r^{576 / 577}\right)$-ERK1/2, and the other parallel GIT1-independent integrin $\beta 1$-FAK(Tyr $\left.{ }^{397}\right)$-ERK1/2.

(c) 2018 The Author(s)

Published by S. Karger AG, Basel

\section{Introduction}

Periodic mechanical stress is advantageous to simulate in vivo physiological mechanical conditions and the mitogenic effects on chondrocytes have been demonstrated $[1,2]$. However, the mechanisms of the transduction of mechanical stimuli and biochemical signaling events are still poorly understood in chondrocytes.

GIT1 is a multidomain protein with intrinsic tyrosine kinase activity. Structurally, GIT1 consists of an N-terminal ARF-GAP domain, ankyrin repeats, Spa homology domain (SHD), synaptic localization domain (SLD), and paxillin-binding site (PBS) [3]. GIT1, as a scaffold protein, is involved in controlling downstream signaling cascades transduction including ERK1/2 MAPKs, and the biological functions of GIT1 are diverse [4-7]. Several researchers and our collaborator Professor Yin have established that GIT1 can be activated by mechanical stimuli besides biochemical stimulation [8, 9]. Kim-Kaneyama and co-workers reported that GIT1 is essential for regulating the contractile capability of smooth-muscle cells in the stress fibers under uni-axial cyclic stretching [10]. Zhao et al. confirmed dependence of Methyl-CpG binding protein 2 (MeCP2)-induced the activation of ERK1/2 signals and cell proliferation on GIT1 in gastric cancer cells [11]. Furthermore, a recent study by another Dr. Zhao proved that chemical stimuli (platelet-derived growth factor, PDGF)-enhanced chondrocyte activity and functions was dependent on activated GIT1 [12]. However, it is similarly unclear whether GIT1 is stimulated, and the specific functions of GIT1 involved in modulating mechanical stress-initiated mitogenic effects, including the nature of any functional association between GIT1 and ERK1/2 in this context, remain to be elucidated in chondrocytes.

Accumulating evidence supports that GIT1 is tightly linked to integrin signaling transduction pathways in some cell types $[13,14]$. The activation of GIT1 by integrin has recently been demonstrated to be a signaling transduction mechanism in breast tumor cells and perivascular mural cells for the detection and response to various extracellular stimuli $[15,16]$. And our previous study found periodic mechanical stress activates integrin $\beta 1$ initiated signaling to promote mitogenic effects in chondrocytes [17]. The coincidence raises the possibility that there may be some causal relationship between integrin $\beta 1$ and GIT1 in chondrocytes in this context. However, different cell types, different systems, and even different mechanical stimuli may result in different activation patterns of signaling pathways.

Our previous findings collectively suggested that periodic mechanical stress promotes rat chondrocyte proliferation through at least two pathways, integrin $\beta 1$-SrcFAK(Tyr(576/577))-ERK1/2 and integrin $\beta 1$-FAK (Tyr(397))-ERK1/2 [18]. And GIT1 can be stimulated by integrin signal-associated proteins and interact with the latter, and anchor potential downstream signaling molecules, activating intracellular signaling cascades [12, $19,20]$. Interaction between FAK and GIT1 within signal transduction has been analyzed in several non-chondrocytic cell types, however, the conclusions are controversial [21-23]. Furthermore, the association between Src and GIT1 has not been determined in chondrocytes subjected to mechanical stimuli. Thus, the elucidation of the relationship between GIT1 and Src, FAK are essential in chondrocytes in this setting.

This study aimed to determine whether GIT1 activates ERK1/2 mitogenic signals in chondrocytes under periodic mechanical stress. Additionally, the nature of the association between GIT1 and integrin $\beta 1$, Src, FAK was analyzed in this system, in order to establish the mechanotransduction pathways and link these signals into mitogenic cascades. 


\section{Cellular Physiology Cell Physiol Biochem 2018;50:1015-1028 and Biochemistry \begin{tabular}{l|l} 
DOI: 10.1159/000494513 & $\begin{array}{l}\text { (c) } 2018 \text { The Author(s). Published by S. Karger AG, Basel } \\
\text { www.karger.com/cpb }\end{array}$
\end{tabular}

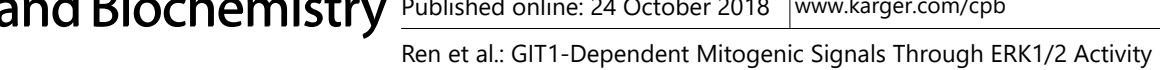

\section{Materials and Methods}

\section{Materials}

Two-week-old Sprague-Dawley rats of either sex were provided by the Animal Center of Nanjing Medical University. Dulbecco's modified Eagle's medium-nutrient mixture (DMEM) F-12, fetal bovine serum, trypsin, collagenase II, and anti-collagen monoclonal antibody II were purchased from Gibco (USA). Type II collagen was purchased from Sigma (USA). Cell counting kit-8 (CCK-8) was purchased from Beyotime Institute of Biotechnology (China). Anti-GIT1, anti-phospho-GIT1 (Tyr ${ }^{321}$ ), anti-Src, anti-phospho-Src (Tyr ${ }^{418}$ ), anti-FAK, anti-phospho-FAK $\left(\mathrm{Tyr}^{397}\right)$, anti-FAK, anti-phospho-FAK $\left(\mathrm{Tyr}^{576 / 577}\right)$, anti-ERK1/2, anti-phospho-ERK1/2 $\left(\mathrm{Thr}^{202} / \mathrm{Tyr}^{204}\right)$, horseradish peroxidase-goat anti-rabbit IgG, and enhanced chemiluminescence (ECL) assay kit were supplied by Cell Signaling Technology Co., Ltd. (USA). Blocking antibody against integrin $\beta 1$ and PP2 were purchased from BD Biosciences (USA) and BIOMOL (USA), respectively. GIT1 short hairpin RNA (shRNA) lentiviral particles, Src shRNA lentiviral particles, Control shRNA lentiviral particles, and Polybrene were supplied by Santa Cruz (USA). The GV287 vector was obtained from GENECHEM (China). The GIT1 mutant $\left(\mathrm{Tyr}^{321}\right.$ to $\mathrm{Phe}^{321}$ ) and FAK mutants $\left(\mathrm{Tyr}^{397}\right.$ to $\mathrm{Phe}^{397}$ and $\mathrm{Tyr}^{576}-\mathrm{Tyr}^{577}$ to $\mathrm{Phe}^{576}-\mathrm{Phe}^{577}$ ) were generated via site-directed mutagenesis using overlapping PCR and subcloned into the GV287 vector. The successful introduction of mutations was verified by sequencing. Wild-type GIT1 and FAK cDNA was subcloned into the GV287 vector served as the control.

A cell incubator (Hereus BB 5060), air-tight cell culture device and reciprocating pressure pump, barrier-type pressure transducer and inversion microscope equipped with camera system were bought from Hereus (Germany), Taixing Experimental Instrument Factory (China), Tianjin Plastics Research Institute (China) and Olympus (Japan), respectively.

\section{Cell culture}

Chondrocytes were harvested using the method described by Séguin and Bernier [24]. The cells were purified by repeated adherence, and the morphology was observed under an inverted phase contrast microscope by staining for collagen type II according to the conventional ABC method. The cells of the second generation were seeded on a glass slide $\left(25 \times 25 \mathrm{~mm}^{2}\right)$ coated with type II collagen at a density of $10^{5}$. Experiments were performed when the cells were approximately 70-80 \% confluent. After experiments, cells were collected for proliferation studies, and total protein was extracted and prepared for Western blot analysis.

\section{Inhibitors}

Blocking antibody against integrin $\beta 1$ and PP2 were used as specific inhibitors against integrin $\beta 1$ and Src, respectively. Blocking antibody against integrin $\beta 1$ was dissolved in DMEM, and PP2 was dissolved in anhydrous dimethylsulfoxide (DMSO). Cells were pretreated with PP2 $(10 \mu \mathrm{M})$ or an equivalent amount of DMSO $(0.1 \% \mathrm{v} / \mathrm{v})$ for $1 \mathrm{~h}$. The remaining cells were pretreated with blocking antibodies against integrin $\beta 1$ $(10 \mu \mathrm{g} / \mathrm{mL})$ or an equivalent amount of DMEM for $5 \mathrm{~h}$.

\section{Construction of a periodical mechanical stress field}

A periodic stress field of perfusion culture system with adjustable stress intensity and frequency was built by connecting the reciprocating intensifier pump to the air-tight cell culture device through a barriertype pressure transducer, as previously described [25]. The pressure in this system ranged from 0 to $300 \mathrm{kPa}$ and the frequency from 0 to $1 \mathrm{~Hz}$. Earlier, it was shown that rabbit chondrocytes subjected to stress varying from 0 to $200 \mathrm{kPa}$ at $0.1 \mathrm{~Hz}$ yielded tissue-engineered cartilage of the best quality [26, 27]. Accordingly, a pressure range of $0-200 \mathrm{kPa}$ and $0.1 \mathrm{~Hz}$ frequency were used in the current study.

\section{Experimental grouping}

Two steps were undertaken in the experiment. In the first step, the cells were maintained under nonpressure conditions or periodic mechanical stress for $1 \mathrm{~h}$ prior to Western blot analysis. In the second step, the cells were pretreated with shRNA targeted to GIT1 or Src or control scrambled shRNA, respectively, or transfected with GIT1 wild-type or GIT1 mutant Y321F, or FAK wild-type or FAK mutant Y397F or Y576F/ Y577. Moreover, the cells were pretreated with blocking antibody against integrin $\beta 1$ or PP2. Then the cells 


\section{Cellular Physiology Cell Physiol Biochem 2018;50:1015-1028 \begin{tabular}{l|l} 
and Biochemistry Published online: 24 October 2018 & $\begin{array}{l}\text { (c) } 2018 \text { The Author(s). Published by S. Karger AG, Basel } \\
\text { www.karger.com/cpb }\end{array}$
\end{tabular}}

Ren et al.: GIT1-Dependent Mitogenic Signals Through ERK1/2 Activity

were maintained under non-pressure conditions or periodic mechanical stress for $1 \mathrm{~h}$ prior to Western blot analysis, and for 3 days, $8 \mathrm{~h}$ per day, prior to direct cell counting and CCK-8 assay, respectively. All groups of cells involved in the experiments were incubated at $37{ }^{\circ} \mathrm{C}$ in the incubator with $5 \% \mathrm{CO}_{2}$.

\section{Western blot analysis}

Total protein was prepared and Western blot analyses were performed as previously described [28]. Total protein was analyzed for protein concentration using Bradford assay. Protein samples were resolved by sodium dodecyl sulfate polyacrylamide gel electrophoresis and transferred onto nitrocellulose membranes. Following blocking for $1 \mathrm{~h}$ with $5 \%$ milk in Tris-buffered saline and Tween 20, the membranes were incubated with antibodies (1:1000 dilution for three antibodies) overnight at $4{ }^{\circ} \mathrm{C}$. The blots were then incubated with horseradish peroxidase-conjugated secondary antibody at room temperature for $1 \mathrm{~h}$ and developed colors with ECL. The results were scanned using Gel Imaging System (UVP Company, USA) and measured using Gel-Pro Analyzer software (Media Cybernetics, USA).

\section{Proliferation Studies}

Proliferation studies were assessed by two different methods: direct cell counting and CCK-8 assay.

\section{Direct cell counting}

The cells were trypsinized and counted as previously described [29]. The cell number was determined by counting each piece of glass slide independently. Each group included six random pieces of glass slides and the experiments were repeated five times.

\section{CCK-8 assay}

Cell proliferation was determined by using CCK-8 solution according to the manufacturer's instruction as previously described [30]. The cells were kept in five 96-well plates $(n=5) ; 10 \mu \mathrm{L}$ of CCK8 solution was added to each well and incubated for $4 \mathrm{~h}$ at $37^{\circ} \mathrm{C}$. The absorbance of each well was finally determined at $450 \mathrm{~nm}$ using a microplate reader.

\section{Statistical analysis}

Statistical analyses were performed using SPSS 14.0 software (SPSS, IL, USA). All the experimental steps were repeated 5 times, and the results were expressed as mean \pm standard deviation. Student's unpaired $t$ tests were used to determine the statistical significance. A $P$ value of 0.05 was considered to be significant.

\section{Results}

Effects of Periodic Mechanical Stress on GIT1 Phosphorylation

The phosphorylation levels of GIT1 at $\mathrm{Tyr}^{321}$ at $1 \mathrm{~h}(0.85 \pm 0.054)$ increased significantly in the pressure group compared to the non-pressure group $(0.36 \pm 0.045)$ (Fig. 1).

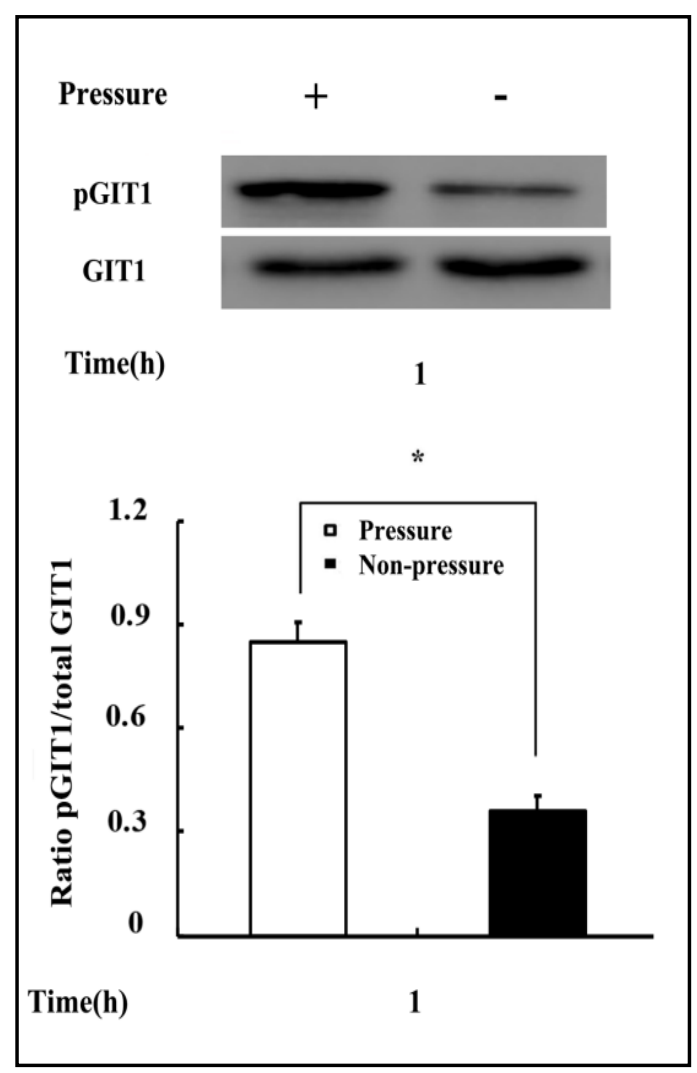

Fig. 1. Effects of periodic mechanical stress on the phosphorylation of GIT1 at Tyr ${ }^{321}$ (pGIT1-Y321). Rat chondrocytes were cultured in vitro for $1 \mathrm{~h}$ with or without periodic mechanical stress. The expression and phosphorylation levels of GIT1 (pGIT1-Y321) were detected by Western blotting. The total amount of protein served as a control. Gray values are represented with a histogram ( $\mathrm{n}=$ $5,{ }^{*} \mathrm{P}<0.05$ for each). The aforementioned images are representative results of Western blotting. 
A

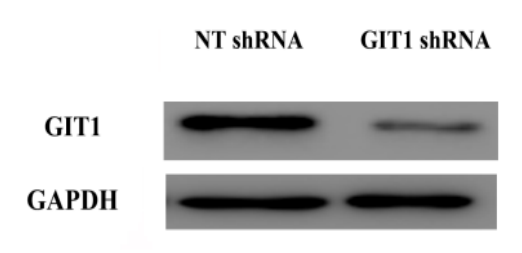

B

C
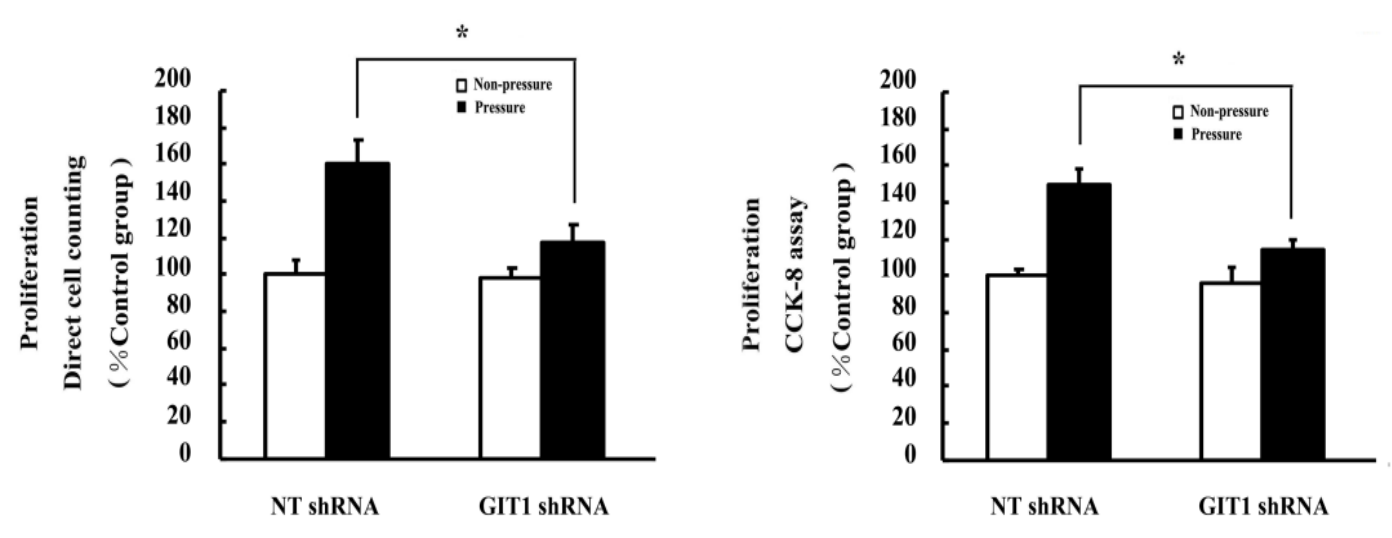

Fig. 2. Effects of GIT1 on chondrocyte proliferation under conditions of periodic mechanical stress. Rat chondrocytes were transfected with shRNA targeted to GIT1 or with nontargeting sequences prior to lysis and Western blotting for GIT1 protein. Transfection with shRNA for GIT1 achieved about a 50\% reduction in GIT1 protein level (A). After pretreatment with control or GIT1 shRNA, rat chondrocytes were cultured in vitro for 3 days under non-pressure conditions or conditions of periodic mechanical stress $8 \mathrm{~h}$ per day prior to proliferation studies. Chondrocyte proliferation was analyzed using direct cell counting (B) and CCK-8 assay (C). The data were expressed as mean \pm standard deviation. We divided the data of all groups by the mean of the control group, and got a percentage to complete the normalization. Chondrocyte proliferation results are shown in the histogram $\left(n=5,{ }^{*} \mathrm{P}<0.05\right.$ for each).

GIT1 and GIT1-Tyr ${ }^{321}$ Are Required for Periodic Mechanical Stress-initiated Chondrocyte Proliferation

GIT1 inhibition with targeted shRNA blocked periodic mechanical stress-induced chondrocyte proliferation significantly (118 \pm 9 (Direct cell counting); $114 \pm 6$ (CCK-8 assay)) compared with chondrocytes in the control group (160 \pm 13 (Direct cell counting); $150 \pm$ 8 (CCK-8 assay)) in response to periodic mechanical stress (Fig. 2). Periodic mechanical stress-induced chondrocyte proliferation significantly reduced in chondrocytes transfected with GIT1 mutant-expressing plasmid ( $\mathrm{Phe}^{321}$ ) (130 \pm 4 (Direct cell counting); $124 \pm 4$ (CCK-8 assay)), compared with those transfected with GIT1 wild-type (165 \pm 11 (Direct cell counting); $153 \pm 5$ (CCK-8 assay)) (Fig. 3).

Integrin $\beta 1$ and Src Are Required for Periodic Mechanical Stress-induced GIT1 Phosphorylation

Pretreatment with blocking antibody against integrin $\beta 1$ attenuated significantly periodic mechanical stress-induced GIT1-Tyr ${ }^{321}$ phosphorylation $(0.51 \pm 0.039)$ in chondrocytes under conditions of periodic mechanical stimulation, compared with those in the control groups $(0.81 \pm 0.044)$ (Fig. $4 \mathrm{~A})$. Src inhibition by PP2 pretreatment and shRNA targeted to Src abrogated significantly the levels of GIT1-Tyr ${ }^{321}$ phosphorylation (0.56 \pm 0.051 (PP2); $0.48 \pm 0.039$ (Src shRNA)) in chondrocytes under conditions of mechanical stress, compared with those in the control groups (0.83 \pm 0.038 (DMSO); $0.81 \pm 0.041$ (NT shRNA)) (Fig. 4B and 4 C). 


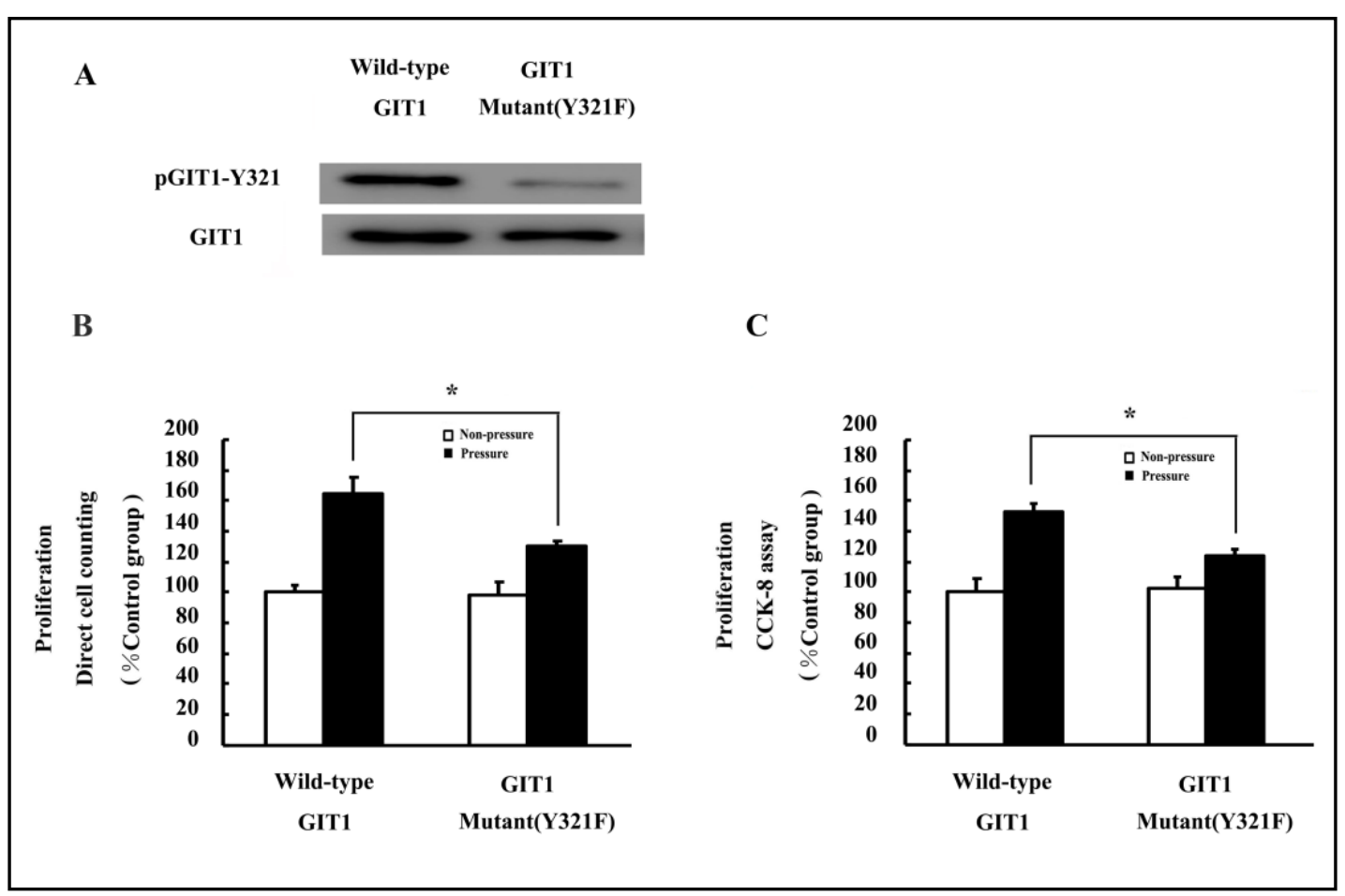

Fig. 3. Effects of GIT1-Tyr ${ }^{321}$ on chondrocyte proliferation under conditions of periodic mechanical stress. Rat chondrocytes were transfected with a GFP-tagged GIT1 wide-type GV287 vector or GV287 expression mutant GIT1 (Tyr ${ }^{321}$ to Phe $^{321}$ ). Phosphorylation of GIT1-Tyr ${ }^{321}$ in the GIT1-Phe ${ }^{321}$ group was significantly abolished, compared with that in the wide-type group (A). Rat chondrocytes were cultured for 3 days under non-pressure conditions or conditions of periodic mechanical stress $8 \mathrm{~h}$ per day prior to proliferation studies. Chondrocyte proliferation was analyzed using direct cell counting (B) and CCK-8 assay (C). Chondrocyte proliferation results are shown in the histogram ( $n=5,{ }^{*} \mathrm{P}<0.05$ for each).

FAK-Tyr ${ }^{397}$ and FAK-Tyr ${ }^{576 / 577}$ Are Not Required for Periodic Mechanical Stress-induced GIT1 Phosphorylation

Periodic mechanical stress-induced GIT1-Tyr ${ }^{321}$ activation was not affected in chondrocytes transfected with FAK mutant-expressing plasmids ( $\mathrm{Phe}^{397}$ and $\left.\mathrm{Phe}^{576 / 577}\right)(0.83$ $\pm 0.031\left(\mathrm{Phe}^{397}\right) ; 0.78 \pm 0.042\left(\mathrm{Phe}^{576 / 577}\right)$ ), compared with those transfected with FAK wildtype (0.79 \pm 0.049 (Wild type); $0.82 \pm 0.033$ (Wild type)) (Fig. 5).

GIT1 Are Not Required for Periodic Mechanical Stress-induced Src and FAK-Tyr ${ }^{397}$ Phosphorylation

Periodic mechanical stress-induced Src-Tyr ${ }^{418}$ and FAK-Tyr ${ }^{397}$ activation did not decrease in chondrocytes transfected with GIT1 mutant-expressing plasmids (Phe $\left.{ }^{321}\right)(0.45 \pm 0.019$ (Src); $0.74 \pm 0.033$ (FAK-Tyr ${ }^{397}$ )), compared with those transfected with FAK wild-type (0.48 \pm 0.033 (Src); $0.76 \pm 0.015$ (FAK-Tyr ${ }^{397}$ ) (Fig. 6A and 6B).

GIT1 Inhibition Prevents Periodic Mechanical Stress-induced FAK-Tyr $r^{576 / 577}$ and ERK1/2 Phosphorylation

Inhibition of GIT1 with shRNA targeted to GIT1 prevented significantly periodic mechanical stress-induced FAK-Tyr ${ }^{576 / 577}$ and ERK1/2 activation in chondrocytes under mechanical conditions $\left(0.42 \pm 0.028\right.$ (FAK-Tyr $\left.{ }^{576 / 577}\right) ; 0.58 \pm 0.036($ ERK1/2)), compared with those in the control groups (0.68 \pm 0.039 (FAK-Tyr ${ }^{576 / 577}$ ); $0.94 \pm 0.042$ (ERK1/2)) (Fig. 6C and 6D). 


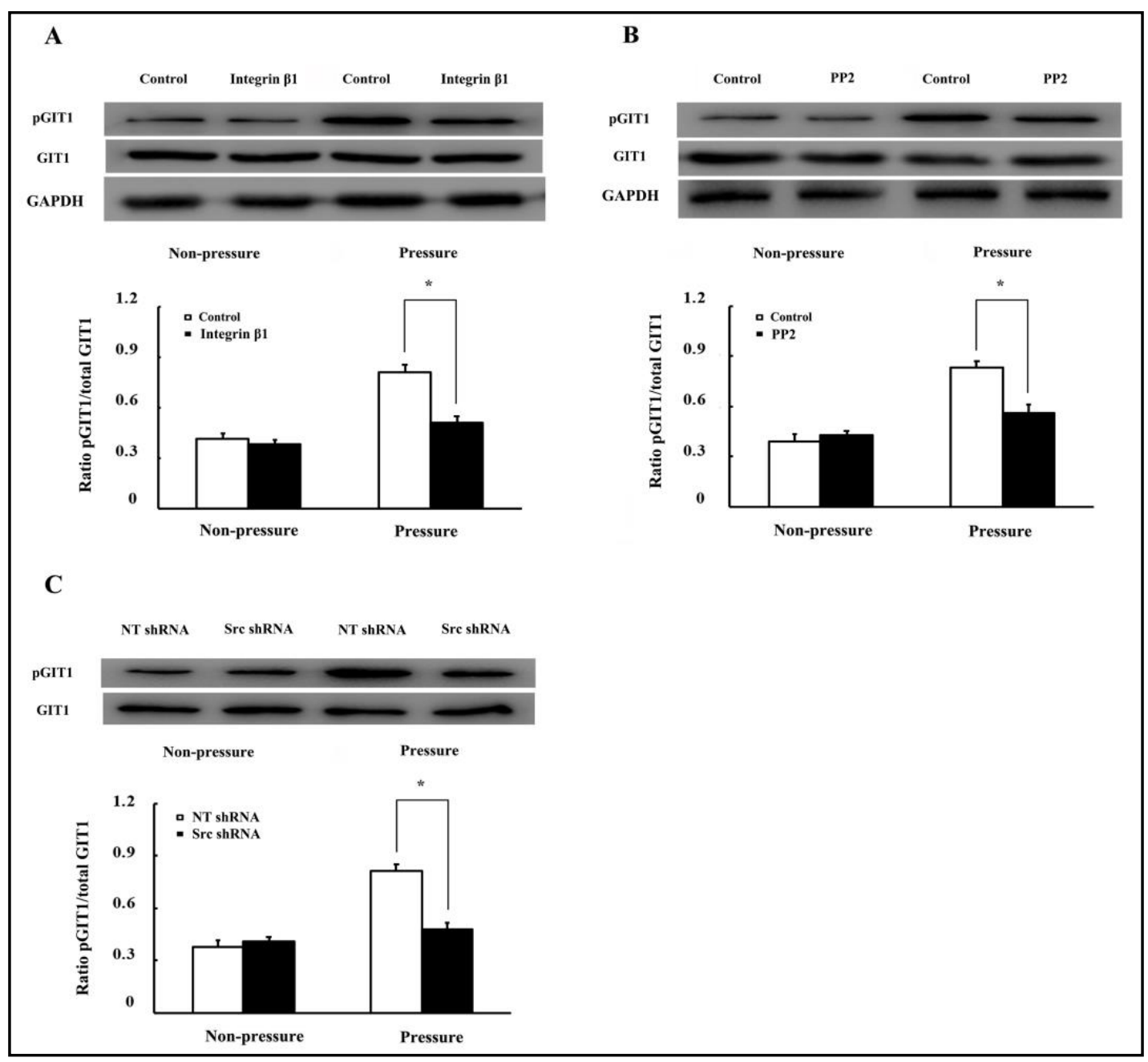

Fig. 4. Effects of integrin $\beta 1$ and Src on the expression and phosphorylation of GIT1 at Tyr ${ }^{321}$ under conditions of periodic mechanical stress. After pretreatment with DMEM or blocking antibody against integrin $\beta 1$ (A), or DMSO or Src inhibitor PP2 (B), or NT sequence or Src shRNA (C), rat chondrocytes were cultured in vitro for $1 \mathrm{~h}$ with or without periodic mechanical stress. The expression and phosphorylation levels of GIT1 (pGIT1-Y321) were detected by Western blotting. The total amount of each protein served as one control (GAPDH served as the other control in A and B, to eliminate the influence of inhibitors on the expression of GIT1). Gray values are represented with a histogram ( $n=5,{ }^{*} \mathrm{P}<0.05$ for each). The aforementioned images are representative results of Western blotting.

GIT1-Tyr ${ }^{321}$ Inhibition Prevents Periodic Mechanical Stress-induced FAK-Tyr ${ }^{576 / 577}$ and ERK1/2 Phosphorylation

Inhibition of GIT1-Tyr ${ }^{321}$ with GIT1 mutant-expressing plasmid $\left(\mathrm{Phe}^{321}\right.$ ) prevented significantly periodic mechanical stress-induced FAK-Tyr ${ }^{576 / 577}$ and ERK1/2 activation in chondrocytes under mechanical conditions $\left(0.47 \pm 0.023\right.$ (FAK-Tyr $\left.{ }^{576 / 577}\right) ; 0.62 \pm 0.041$ (ERK1/2)), compared with those in the control groups $\left(0.66 \pm 0.019\left(\right.\right.$ FAK-Tyr $\left.^{576 / 577}\right) ; 0.89 \pm$ 0.024 (ERK1/2)) (Fig. 7). 


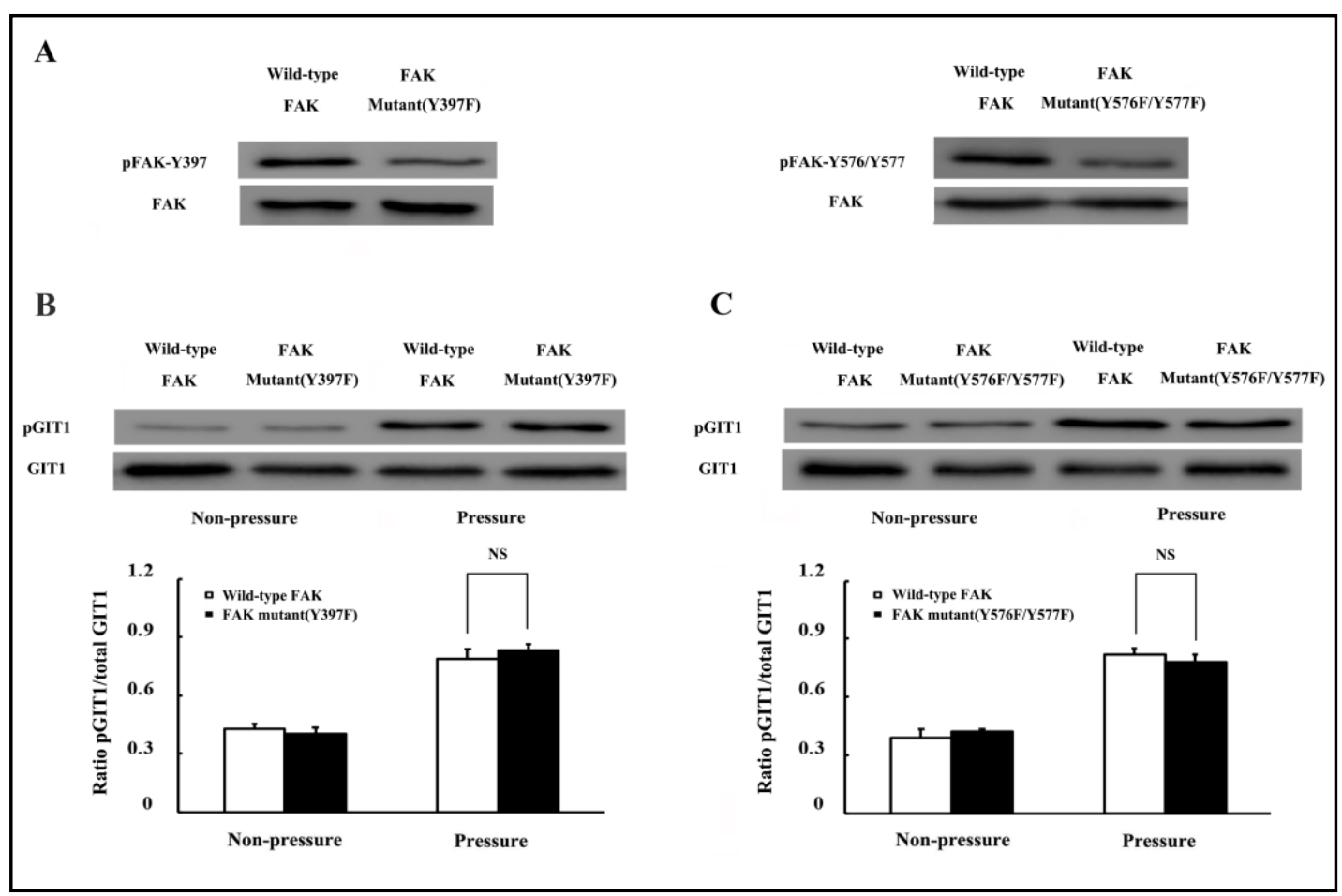

Fig. 5. Effects of FAK-Tyr ${ }^{397}$ and FAK-Tyr ${ }^{576 / 577}$ on the expression and phosphorylation of GIT1 under conditions of periodic mechanical stress. Rat chondrocytes were transfected with a GFP-tagged FAK wide-type GV287 vector or GV287 expression mutants FAK (Tyr ${ }^{397}$ to $\mathrm{Phe}^{397}$ and $\mathrm{Tyr}^{576 / 577}$ to $\mathrm{Phe}^{576 / 577}$ ). Phosphorylation of FAK-Tyr ${ }^{397}$ in the FAK-Phe ${ }^{397}$ group and phosphorylation of FAK-Tyr ${ }^{576 / 577}$ in the FAKPhe ${ }^{576 / 577}$ group were significantly abolished, respectively, compared with those in the wide-type group (A). Rat chondrocytes were cultured in vitro for $1 \mathrm{~h}$ with or without periodic mechanical stress. The expression and phosphorylation levels of GIT1 (pGIT1-Y321) were detected by Western blotting (B: FAK Mutant (Y397F); C: FAK Mutant (Y576F/Y577F)). The total amount of each protein served as a control. Gray values are represented with a histogram $n=5,{ }^{*} \mathrm{P}<0.05$ for each). The aforementioned images are representative results of Western blotting. 
A

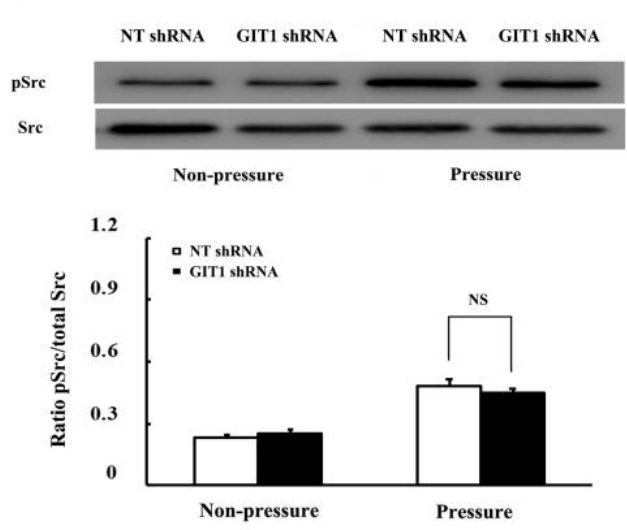

C

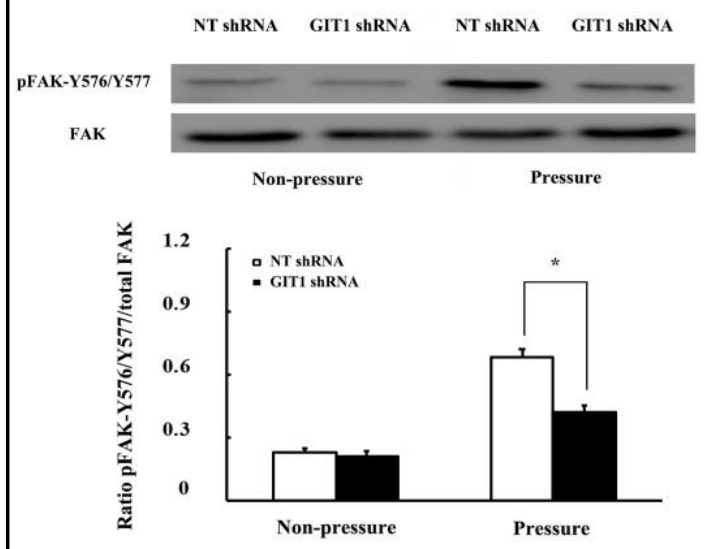

\section{B}

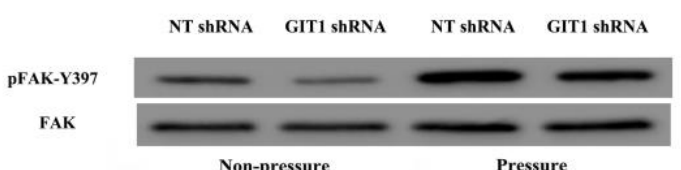

Non-pressure

Pressure

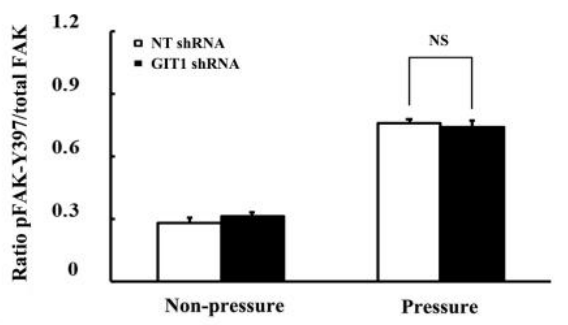

D

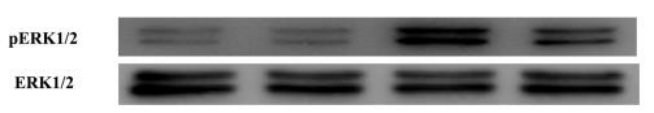

Non-pressure Pressure

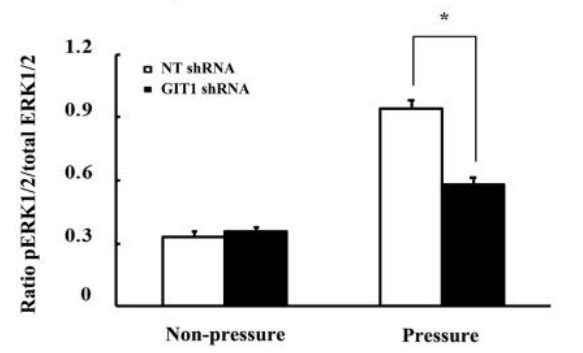

Fig. 6. Effects of GIT1 on the expression and phosphorylation of Src, FAK (Tyr ${ }^{397}$ and Tyr ${ }^{576 / 577}$ ) and ERK1/2 under conditions of periodic mechanical stress. After pretreatment with NT sequence or GIT1 shRNA, rat chondrocytes were cultured in vitro for $1 \mathrm{~h}$ with or without periodic mechanical stress. The expression and phosphorylation levels of Src (A), FAK $\left(\operatorname{Tyr}^{397}\right.$ (B) and $\operatorname{Tyr}^{576 / 577}$ (C)) and ERK1/2 (D) were detected by Western blotting. The total amount of each protein served as a control. Gray values are represented with a histogram $n=5,{ }^{*} \mathrm{P}<0.05$ for each). The aforementioned images are representative results of Western blotting. 


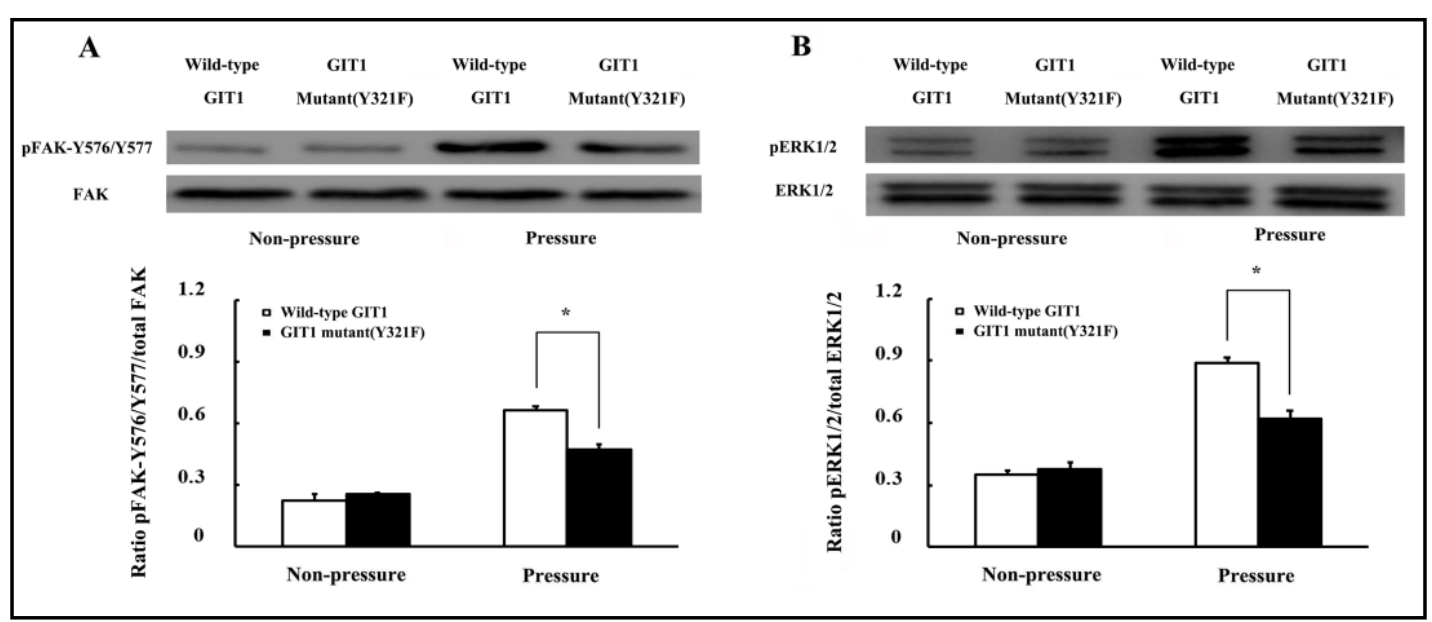

Fig. 7. Effects of GIT1-Tyr ${ }^{321}$ on the expression and phosphorylation of FAK (Tyr ${ }^{576 / 577}$ ) and ERK1/2 under conditions of periodic mechanical stress. Rat chondrocytes were transfected with a GFP-tagged GIT1 widetype GV287 vector or GV287 expression mutant GIT1 $\left(\mathrm{Tyr}^{321}\right.$ to $\mathrm{Phe}^{321}$ ). Rat chondrocytes were cultured in vitro for $1 \mathrm{~h}$ with or without periodic mechanical stress. The expression and phosphorylation levels of FAK $\left(\mathrm{Tyr}^{576 / 577}\right)(\mathrm{A})$ and ERK1/2 (B) were detected by Western blotting. The total amount of each protein served as a control. Gray values are represented with a histogram $n=5,{ }^{*} \mathrm{P}<0.05$ for each. The aforementioned images are representative results of Western blotting.

\section{Discussion}

Periodic mechanical stress induction of chondrocyte proliferation may be mediated through a process of signaling transduction, integrating these signals into cellular responses. Our present findings demonstrated that GIT1 and GIT1-Tyr ${ }^{321}$ are required for integrin $\beta 1$ ERK1/2 mitogenic signaling cascade in chondrocytes in response to periodic mechanical stress.

The catalytic functions of GIT1 are dependent on the phosphorylation of tyrosine residues, which affects various cellular activities [31]. Webb used mass spectrometry to generate a phosphorylation map of GIT1, among potential tyrosine residues, $\mathrm{Tyr}^{321}$ was suggested to be a possible activated phosphorylation site [32]. And Yin has previously shown that GIT1-Tyr ${ }^{321}$ is a key regulator of bone mass and osteoblast cell migration [6]. We observed that periodic mechanical stress statistically and significantly enhanced the phosphorylation of GIT1 at Tyr ${ }^{321}$ in chondrocytes. Moreover, depletion of GIT1 with shRNA abolished chondrocyte proliferation following periodic mechanical stimuli. These results provide definitive evidence to support the participation of GIT1 signaling in the regulation of the mitogenic responses to periodic mechanical stimulation in chondrocytes. Meanwhile, GIT1 Y321F mutant resulted in blockage of cell proliferation in this system. This is a novel discovery that clearly highlighted the significance of site-specific tyrosine residue within GIT1 in chondrocytic adaption to physical mechanical stimuli. Despite the importance of GIT1-Tyr ${ }^{321}$ in mediating the mechanotransduced mitogenic effects, it is possible that other phosphorylation residues within GIT1 may also play an indispensable role in chondrocytes.

The activation sites in the domain of GIT1 allow for specific binding, which is essential for several downstream transduction signal events [11, 33, 34]. A study by Pang and his colleagues documented that vascular endothelial growth factor (VEGF)-initiated ERK1/2 phosphorylation is dependent on the activation of GIT1 modulating pulmonary vascular behavior and functions [5]. In the present study, the inhibition of GIT1 by targeted shRNA was found to abrogate the activation of ERK1/2, suggesting that GIT1 activation of ERK1/2 contributes to the mechanism by which chondrocytes respond to physical mechanical stimulation. Moreover, pretreatment with GIT1 Y321F mutant prevented ERK1/2 phosphorylation stimulated by periodic mechanical stress. Therefore, it could 


\section{Cellular Physiology Cell Physiol Biochem 2018;50:1015-1028 \begin{tabular}{ll|l} 
DOI: 10.1159/000494513 & $\begin{array}{l}\text { O } 2018 \text { The Author(s). Published by S. Karger AG, Basel } \\
\text { www.karger.com/cpb }\end{array}$
\end{tabular}

be concluded that activation of GIT1 at Tyr $^{321}$ seemed to mediate at least some mitogenic mechanotransduced signals through ERK1/2 MAPKs in chondrocytes.

Increasing evidence has concluded that the relationship between GIT1 and Src, FAK is complex and still controversial in diverse complex signaling pathways [35-38]. Zhang et al. demonstrated that endothelins stimulation of endothelial nitric-oxide synthase (eNOS) in sinusoidal endothelial cells is initiated by activated GIT1 through a Src signaling transduction mechanism [19]. Instead of being activated by a GIT1-dependent mechanism, the inhibition of cyclic mechanical stress-stimulated GIT1-Tyr ${ }^{321}$ by PP2 or shRNA targeted to Src, suggested that Src might be responsible for the initial GIT1 activation in the present study. This was consistent with other observation of Src modulation and interaction with GIT1 in other cell types in different systems $[22,39]$. However, this may not be universally true, and Src and GIT1 signals can also act in parallel in human liver and colon cancer cells and in other settings [35].

GIT1 may also be activated by other signaling proteins, such as FAK, and mechanosensors following mechanical stimulation. Tyrosine phosphorylation at different sites within FAK is catalyzed in distinct ways and affects various cellular functions. Our previous study and works by others regarding FAK activity mainly concentrate on the $\mathrm{Tyr}^{397}$ and $\mathrm{Tyr}^{576 / 577}$ phosphorylation sites in chondrocytes and other cell types under mechanical stimulation $[18,40]$. In our experiments, transfected with FAK Y397F or Y576/577F mutants did not decrease periodic mechanical stress-enhanced GIT1 activation in chondrocytes, while GIT1 inhibition by shRNA targeted to GIT1 and GIT1 Y321F mutant attenuated FAK phosphorylation at $\mathrm{Tyr}^{576 / 577}$, but not $\mathrm{Tyr}^{397}$. Based on the results, we can provide definitive evidence to support that GIT1 activation of FAK at $\mathrm{Tyr}^{576 / 577}$, but not $\mathrm{Tyr}^{397}$, is responsible for the signaling transduction mechanisms in chondrocytes under conditions of cyclic mechanical stimulation. Meantime, based on our present and previous results, periodic mechanical stress-activated GIT1 and Tyr ${ }^{397}$ signals may act in parallel in this setting.

Recently, GIT1 was viewed as an important integrin-associated kinase that receives and transmits various integrin-initiated intracellular biochemical signals [16, 41, 42]. The activation of GIT1 by integrin has been reported to be a signaling transduction mechanism. However, this is still obscure in chondrocytes under mechanical stimulation. Our present study revealed that pretreatment with an integrin $\beta 1$ functional blocking antibody abrogated the activation of GIT1-Tyr ${ }^{321}$ in chondrocytes under periodic mechanical stress conditions. These data above demonstrate the concept that integrin $\beta 1$, as a proximal mechanosensor, play a key role in the signals that lead to the increased GIT1 activation and subsequent chondrocyte proliferation in response to physical mechanical stress. Our present observation seems consistent with a study on vascular stability, cerebral angiogenesis and endothelial cell proliferation in the developing embryo disclosed that GIT1 phosphorylation is mediated by activation of cell-surface integrin [15].

\section{Conclusion}

In conclusion, GIT1 is a crucial decision-making protein participating in chondrocytic ERK1/2 mitogenic signals initiated by periodic mechanical stress. Specifically, based on the current and previous results, two activated signaling pathways converge on ERK1/2: one requires activation of Src and is GIT1-dependent, which stimulates activated FAK-Tyr ${ }^{576 / 577}$, and the other whereby separate phosphorylation at $\mathrm{Tyr}^{397}$ occurs independently of Src and GIT1, although both pathways are initiated by integrin $\beta 1$. 


\section{Cellular Physiology Cell Physiol Biochem 2018;50:1015-1028 \begin{tabular}{ll|l} 
DOI: 10.1159/000494513 & $\begin{array}{l}\text { (c) } 2018 \text { The Author(s). Published by S. Karger AG, Basel } \\
\text { www.karger.com/cpb }\end{array}$
\end{tabular}}

Ren et al.: GIT1-Dependent Mitogenic Signals Through ERK1/2 Activity

\section{Acknowledgements}

This work was supported by the National Natural and Science Foundation (81501874), Jiangsu Province Health and Family Planning Commission Foundation (Q201511 and QNRC2016139) (all foundations to Kewei Ren); The Project of Invigorating Health Care through Science, Technology and Education (Jiangsu Provincial Medical Youth Talent), Changzhou High-level Medical Talents Training Project (2016CZBJ029), Jiangsu planned projects for Postdoctoral Research Funds (1701001A) and Changzhou International Scientific and Technology Cooperation Project (CZ20170021) (all foundations to Luming Nong).

\section{Disclosure Statement}

The authors declare that they have no competing interests.

\section{References}

1 Wang PY, Chow HH, Lai JY, Liu HL, Tsai WB: Dynamic compression modulates chondrocyte proliferation and matrix biosynthesis in chitosan/gelatin scaffolds. J Biomed Mater Res B Appl Biomater 2009;91:143152.

-2 Liang W, Zhu C, Liu F, Cui W, Wang Q, Chen Z, Zhou Q, Xu S, Zhai C, Fan W: Integrin beta1 gene therapy enhances in vitro creation of tissue-engineered cartilage under periodic mechanical stress. Cell Physiol Biochem 2015;37:1301-1314.

-3 Yin G, Haendeler J, Yan C, Berk BC: Git1 functions as a scaffold for mek1-extracellular signal-regulated kinase 1 and 2 activation by angiotensin ii and epidermal growth factor. Mol Cell Biol 2004;24:875-885.

-4 Yin G, Zheng Q Yan C, Berk BC: Git1 is a scaffold for erk1/2 activation in focal adhesions. J Biol Chem 2005;280:27705-27712.

5 Pang J, Hoefen R, Pryhuber GS, Wang J, Yin G, White RJ, Xu X, O’Dell MR, Mohan A, Michaloski H, Massett MP, Yan C, Berk BC: G-protein-coupled receptor kinase interacting protein-1 is required for pulmonary vascular development. Circulation 2009;119:1524-1532.

6 Menon P, Yin G, Smolock EM, Zuscik MJ, Yan C, Berk BC: Gpcr kinase 2 interacting protein 1 (git1) regulates osteoclast function and bone mass. J Cell Physiol 2010;225:777-785.

7 Xiao J, Chen X, Xu L, Zhang Y, Yin Q, Wang F: Pdgf regulates chondrocyte proliferation through activation of the git1- and plcgamma1-mediated erk1/2 signaling pathway. Mol Med Rep 2014;10:2409-2414.

-8 Shikata Y, Rios A, Kawkitinarong K, DePaola N, Garcia JG, Birukov KG: Differential effects of shear stress and cyclic stretch on focal adhesion remodeling, site-specific fak phosphorylation, and small gtpases in human lung endothelial cells. Exp Cell Res 2005;304:40-49.

-9 Sheu TJ, Zhou W, Fan J, Zhou H, Zuscik MJ, Xie C, Yin G, Berk BC: Decreased bmp2 signal in git1 knockout mice slows bone healing. Mol Cell Biochem 2014;397:67-74.

10 Kim-Kaneyama JR, Suzuki W, Ichikawa K, Ohki T, Kohno Y, Sata M, Nose K, Shibanuma M: Uni-axial stretching regulates intracellular localization of hic-5 expressed in smooth-muscle cells in vivo. J Cell Sci 2005;118:937-949.

-11 Zhao LY, Tong DD, Xue M, Ma HL, Liu SY, Yang J, Liu YX, Guo B, Ni L, Liu LY, Qin YN, Wang LM, Zhao XG, Huang C: Mecp2, a target of mir-638, facilitates gastric cancer cell proliferation through activation of the mek1/2erk1/2 signaling pathway by upregulating git1. Oncogenesis 2017;6:e368.

12 Zhao GZ, Zhang LQ Liu Y, Fang J, Li HZ, Gao KH, Chen YZ: Effects of platelet-derived growth factor on chondrocyte proliferation, migration and apoptosis via regulation of git1 expression. Mol Med Rep 2016;14:897-903.

13 Sato H, Suzuki-Inoue K, Inoue 0, Ozaki Y: Regulation of adaptor protein git1 in platelets, leading to the interaction between git1 and integrin alpha(iib)beta3. Biochem Biophys Res Commun 2008;368:157-161.

14 Chan SH, Huang WC, Chang JW, Chang KJ, Kuo WH, Wang MY, Lin KY, Uen YH, Hou MF, Lin CM, Jang TH, Tu CW, Lee YR, Lee YH, Tien MT, Wang LH: Microrna-149 targets git1 to suppress integrin signaling and breast cancer metastasis. Oncogene 2014;33:4496-4507. 


\section{Cellular Physiology Cell Physiol Biochem 2018;50:1015-1028 and Biochemistry DOl: 10.1159/000494513 \begin{tabular}{l|l} 
O 2018 The Author(s). Published by S. Karger AG, Basel \\
wwww.karger.com/cpb
\end{tabular}

15 Liu J, Zeng L, Kennedy RM, Gruenig NM, Childs SJ: Betapix plays a dual role in cerebral vascular stability and angiogenesis, and interacts with integrin alphavbeta8. Dev Biol 2012;363:95-105.

-16 Donnelly SK, Cabrera R, Mao SPH, Christin JR, Wu B, Guo W, Bravo-Cordero JJ, Condeelis JS, Segall JE, Hodgson L: Rac3 regulates breast cancer invasion and metastasis by controlling adhesion and matrix degradation. J Cell Biol 2017;216:4331-4349.

17 Ren K, Liu F, Huang Y, Liang W, Cui W, Wang Q, Fan W: Periodic mechanical stress activates integrinbeta1dependent src-dependent plcgamma1-independent rac1 mitogenic signal in rat chondrocytes through erk1/2. Cell Physiol Biochem 2012;30:827-842.

-18 Liang W, Ren K, Liu F, Cui W, Wang Q Chen Z, Fan W: Periodic mechanical stress stimulates the fak mitogenic signal in rat chondrocytes through erk1/2 activity. Cell Physiol Biochem 2013;32:915-930.

-19 Liu S, Premont RT, Rockey DC: Endothelial nitric-oxide synthase (enos) is activated through g-proteincoupled receptor kinase-interacting protein 1 (git1) tyrosine phosphorylation and src protein. J Biol Chem 2014;289:18163-18174.

-20 Brimer N, Wade R, Vande Pol S: Interactions between e6, fak, and git1 at paxillin ld4 are necessary for transformation by bovine papillomavirus 1 e6. J Virol 2014;88:9927-9933.

21 Daher Z, Noel J, Claing A: Endothelin-1 promotes migration of endothelial cells through the activation of arf6 and the regulation of fak activity. Cell Signal 2008;20:2256-2265.

22 Ren Y, Yu L, Fan J, Rui Z, Hua Z, Zhang Z, Zhang N, Yin G: Phosphorylation of git1 tyrosine 321 is required for association with fak at focal adhesions and for pdgf-activated migration of osteoblasts. Mol Cell Biochem 2012;365:109-118.

23 Huang WC, Chan SH, Jang TH, Chang JW, Ko YC, Yen TC, Chiang SL, Chiang WF, Shieh TY, Liao CT, Juang JL, Wang HC, Cheng AJ, Lu YC, Wang LH: Mirna-491-5p and git1 serve as modulators and biomarkers for oral squamous cell carcinoma invasion and metastasis. Cancer Res 2014;74:751-764.

-24 Seguin CA, Bernier SM: Tnfalpha suppresses link protein and type ii collagen expression in chondrocytes: Role of mek1/2 and nf-kappab signaling pathways. J Cell Physiol 2003;197:356-369.

-25 Nong L, Yin G, Ren K, Tang J, Fan W: Periodic mechanical stress enhances rat chondrocyte area expansion and migration through src-plcgamma1-erk1/2 signaling. Eur J Cell Biol 2010;89:705-711.

26 Yue HT, Fan WM, Ma YM: Tissue engineered cartilage in response to diferent cyclic pressure. Xpression in a pkc- andrho kinase-dependent manner. Chin J Orthop Trauma 2007;9:661-664.

27 Zhang GC, Fan WM: Effects of cyclic pressure at different frequendes on the construction of tissueengineering cartilage. Chin J Exp Surg 2007;24:677-678.

28 Wang P, Cao X, Nagel DJ, Yin G: Activation of ask1 during reperfusion of ischemic spinal cord. Neurosci Lett 2007;415:248-252.

29 Chaturvedi LS, Marsh HM, Shang X, Zheng Y, Basson MD: Repetitive deformation activates focal adhesion kinase and erk mitogenic signals in human caco-2 intestinal epithelial cells through src and rac1. J Biol Chem 2007;282:14-28.

-30 Bae JY, Han DW, Wakitani S, Nawata M, Hyon SH: Biological and biomechanical evaluations of osteochondral allografts preserved in cold storage solution containing epigallocatechin gallate. Cell Transplant 2010;19:681-689.

-31 Wu Y, Zhang Y, Yin Q, Xia H, Wang J: Plateletderived growth factor promotes osteoblast proliferation by activating gproteincoupled receptor kinase interactor1. Mol Med Rep 2014;10:1349-1354.

-32 Webb DJ, Mayhew MW, Kovalenko M, Schroeder MJ, Jeffery ED, Whitmore L, Shabanowitz J, Hunt DF, Horwitz AF: Identification of phosphorylation sites in git1. J Cell Sci 2006;119:2847-2850.

-33 Smithson LJ, Gutmann DH: Proteomic analysis reveals git1 as a novel mtor complex component critical for mediating astrocyte survival. Genes Dev 2016;30:1383-1388.

34 Chang JS, Su CY, Yu WH, Lee WJ, Liu YP, Lai TC, Jan YH, Yang YF, Shen CN, Shew JY, Lu J, Yang CJ, Huang MS, Lu PJ, Lin YF, Kuo ML, Hua KT, Hsiao M: Git1 promotes lung cancer cell metastasis through modulating rac1/cdc42 activity and is associated with poor prognosis. Oncotarget 2015;6:36278-36291.

35 Peng H, Li TW, Yang H, Moyer MP, Mato JM, Lu SC: Methionine adenosyltransferase 2b-git1 complex serves as a scaffold to regulate ras/raf/mek1/2 activity in human liver and colon cancer cells. Am J Pathol 2015;185:1135-1144.

-36 Rui Z, Li X, Fan J, Ren Y, Yuan Y, Hua Z, Zhang N, Yin G: Git1y321 phosphorylation is required for erk1/2and pdgf-dependent vegf secretion from osteoblasts to promote angiogenesis and bone healing. Int J Mol Med 2012;30:819-825. 


\section{Cellular Physiology Cell Physiol Biochem 2018;50:1015-1028 \begin{tabular}{ll|l} 
DOl: 10.1159/000494513 & $\begin{array}{l}\text { O } 2018 \text { The Author(s). Published by S. Karger AG, Basel } \\
\text { www.karger.com/cpb }\end{array}$ \\
\hline
\end{tabular}}

Ren et al.: GIT1-Dependent Mitogenic Signals Through ERK1/2 Activity

-37 Wade R, Brimer N, Lyons C, Vande Pol S: Paxillin enables attachment-independent tyrosine phosphorylation of focal adhesion kinase and transformation by ras. J Biol Chem 2011;286:37932-37944.

38 Dong Y, Chang C, Liu J, Qiang J: Targeting of git1 by mir-149* in breast cancer suppresses cell proliferation and metastasis in vitro and tumor growth in vivo. Onco Targets Ther 2017;10:5873-5882.

39 Wang J, Taba Y, Pang J, Yin G, Yan C, Berk BC: Git1 mediates vegf-induced podosome formation in endothelial cells: Critical role for plcgamma. Arterioscler Thromb Vasc Biol 2009;29:202-208.

-40 Lee DY, Li YS, Chang SF, Zhou J, Ho HM, Chiu JJ, Chien S: Oscillatory flow-induced proliferation of osteoblastlike cells is mediated by alphavbeta 3 and beta1 integrins through synergistic interactions of focal adhesion kinase and shc with phosphatidylinositol 3-kinase and the akt/mtor/p70s6k pathway. J Biol Chem 2010;285:30-42.

41 Zhang LQ, Zhao GZ, Xu XY, Fang J, Chen JM, Li JW, Gao XJ, Hao LJ, Chen YZ: Integrin-beta1 regulates chondrocyte proliferation and apoptosis through the upregulation of git1 expression. Int J Mol Med 2015;35:1074-1080.

42 Webb DJ, Zhang H, Majumdar D, Horwitz AF: Alpha5 integrin signaling regulates the formation of spines and synapses in hippocampal neurons. J Biol Chem 2007;282:6929-6935. 